\title{
Effect of Operating Parameters on Electrochemical Discoloration of Acid Blue 1 on BDD Electrode
}

\author{
Z.A. Ayoub and M.M. El Jamal ${ }^{*}$ \\ Inorganic and Organometallic Coordination Chemistry Laboratory (LCIO), \\ Faculty of Sciences (I), Lebanese University, El Hadath, Lebanon
}

Received June 30, 2016; accepted December 9, 2016

\begin{abstract}
The degradation of the $\mathrm{AB} 1$ dye by electro-generated species using a BDD electrode was performed. The results were explained by the generation of $\mathrm{OH}^{*}$ radical, $\mathrm{S}_{2} \mathrm{O}_{8}{ }^{2-}$ in the presence of sulfate, and active halide species in the presence of halide salt. The discoloration rate increases in this order: sulfate, $\mathrm{KCl}, \mathrm{KBr}$. In the presence of $\mathrm{KCl}$, the discoloration is affected by the current density, initial $\mathrm{pH}$, temperature, and concentration of the supporting electrolyte; however, the concentration of the dye and the ionic strength showed a negligible effect. The intermediates produced during the discoloration are a function of the $\mathrm{pH}$ of the solution. In the presence of sulfate, the discoloration rate is very slow, and the mechanism of discoloration is different from that in the presence of $\mathrm{KCl}$. The thermodynamic parameters of the discoloration are calculated.
\end{abstract}

Keywords: BDD electrode; Acid Blue 1; discoloration; kinetic; strong electrolyte.

\section{Introduction}

Synthetic dyes are extensively used in various branches of industry: textile, leather tanning, paper production, cosmetic products, and food technology. Different chemical classes of dyes are frequently employed on industrial scale, such as azo, anthraquinone, sulfur, indigo, and triphenylmethyl derivatives. Due to large-scale production and extensive application, synthetic dyes can cause considerable environmental pollution, and are serious health-risk factors [1- 4]. For this reason, there is a need to apply powerful methods to ensure the complete discoloration and degradation of dyestuffs and their metabolites present in the spent dyeing baths.

Many studies have been carried out to investigate the degradation of the triphenylmethane dyes, such as adsorption [5, 6], biodegradation [7, 8], photocatalytic degradation [9-12], oxidation with persulfate - E133 [13], crystal violet [14], and E131V [15]-, and finally, electrochemical treatment:

\footnotetext{
* Corresponding author. E-mail address: mjamal@ul.edu.lb
} 
alphazurine on BDD electrode [16], crystal violet on BDD [17], methyl violet [18] and malachite green $[19,20]$ have been investigated.

Advanced oxidation processes involve in situ generation of powerful chemical oxidants, such as $\mathrm{OH}^{*}$ and $\mathrm{SO}^{-*}$ for the removal of a wide range of organic contaminants in wastewater. The generation of these oxidants at the BDD electrode surface from the oxidation of an aqueous solution occurred as follows [21-23].

$$
\mathrm{BDD}\left(\mathrm{H}_{2} \mathrm{O}\right) \longrightarrow \mathrm{OH}_{a d s}^{*}+\mathrm{H}^{+}+e^{-} \text {or in basic medium } \mathrm{BDD}\left(\mathrm{OH}^{-}\right) \longrightarrow \mathrm{OH}_{a d s}^{*}+e^{-}
$$

The generation of $\mathrm{SO}_{4}^{*-}$, and $\mathrm{S}_{2} \mathrm{O}_{8}^{2-}$ in an aqueous solution of sulfate could be represented as follows:

$$
\mathrm{OH}^{*}+\mathrm{SO}_{4}^{2-} \longrightarrow \mathrm{SO}_{4}^{-*}+\mathrm{OH}^{-} \quad \text { and } \quad 2 \mathrm{SO}_{4}^{2-} \rightarrow \mathrm{S}_{2} \mathrm{O}_{8}^{2-}+2 e^{-}
$$

Less powerful oxidants, such as $\mathrm{Cl}_{2}$ and $\mathrm{Br}_{2}$, can also be produced in a solution containing halide salt $\left(\mathrm{X}^{-}: \mathrm{Cl}^{-}, \mathrm{Br}^{-}\right)$:

$$
2 X^{-}-2 e^{-} \longrightarrow X_{2}, \quad X_{2}+H_{2} \mathrm{O} \longrightarrow \mathrm{HOX}+H^{+}+X^{-}, \quad H O X \longrightarrow O X^{-}+H^{+}
$$

The $\mathrm{HOX} / \mathrm{OX}^{-}$pair reacts with organic compounds by addition, substitution or oxidation.

Acid blue 1, also called sulfan blue 5 or E131 VF, is a dark greenish synthetic triphenylmethane dye (Fig. 1). It is structurally very similar to the patent blue V and brilliant blue (three phenyl rings with different substituted groups). The mineralization of the mentioned dyes by persulfate failed $[13,15]$.
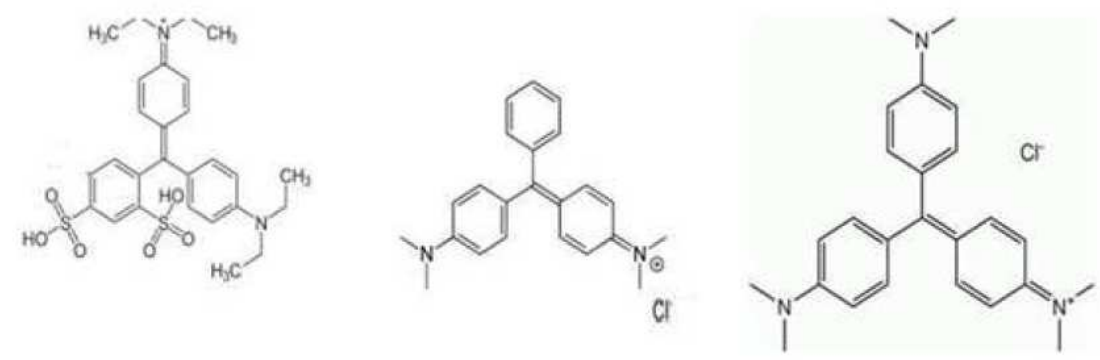

Figure 1. Structure of three triphenylmethane dyes: acid blue 1 (AB1), malachite green (MG), and crystal violet (CV).

The aim of this work is to study the electrochemical oxidation of aqueous solutions containing acid blue 1 (AB1) using a boron-doped diamond electrode. Thus, it is of interest to study the effect of some experimental parameters, such as the nature of the strong electrolyte, $\mathrm{pH}$, temperature, current intensity, and others, on the indirect oxidation of the acid blue 1 on a BDD electrode. 


\section{Experimental}

All chemical reagents used were of analytical grade. The food colorant $A B 1$ is used as purchased from Sigma Aldrich $\left(\mathrm{C}_{27} \mathrm{H}_{31} \mathrm{~N}_{2} \mathrm{O}_{6} \mathrm{~S}_{2}-\mathrm{Na}\right.$, purity: $50 \%$, MW: $565.67 \mathrm{~g}$ ). Stock solution of acid blue 1 (AB1) was prepared by dissolving $40 \mathrm{mg}$ in one liter of distilled water. The concentration of the dye in the reactional mixture was selected in such a way that the absorbance of the dye followed Beer's law. Most of the electrolysis experiments were done at room temperature $(293 \mathrm{~K}), 2 \mathrm{~mA}$ for $\mathrm{KBr}, 5 \mathrm{~mA}$ for $\mathrm{KCl}$ and $20 \mathrm{~mA}$ for $\mathrm{Na}_{2} \mathrm{SO}_{4}$ and $\mathrm{pH} \sim 5$, in presence of $8 \mathrm{mg} \mathrm{L}^{-1}$ of $\mathrm{AB} 1,0.1 \mathrm{M}$, of the strong electrolyte. The experiments were carried out in a single electrolytic cell.

BDD electrodes are bipolar plates $(50 \times 25 \times 2 \mathrm{~mm})$ from NeoCoaT (Switzerland). The distance between the two electrodes was $5 \mathrm{~cm}$ (undivided cell). The electrolysis was done with a Chrono-Amperostat, type CEAMD-6, from Taccusel. Measurements of $\mathrm{pH}$ were carried out using a Schott Gerate CG 819 $\mathrm{pH}$-meter.

The discoloration rate of the food colorant was followed by measuring the absorbance at the maximum wavelength of AB1 $(640 \mathrm{~nm})$. UV- visible spectra were recorded on a double beam UV-visible spectrophotometer, in order to detect any shift in the $\lambda_{\max }$ or the appearance of a new band.

\section{Results and discussion}

\section{Nature of the supporting electrolyte}

The strong electrolyte added to do the electrolysis has a great importance, since, in the first step, it is oxidized at the anode, and in the second step it probably oxidizes the organic compounds present in the solution. Therefore, the intermediates and the final products are a function of the strong electrolyte present in the medium. Four strong electrolytes are used in this study: $\mathrm{KCl}, \mathrm{KBr}$, $\mathrm{KI}$ and $\mathrm{Na}_{2} \mathrm{SO}_{4}$. The electrolysis in the presence of KI produces $\mathrm{I}_{2}$, which is a weak oxidant and, therefore, is not able to attack AB1 dye [the absorbance at 640 $\mathrm{nm}\left(\lambda_{\max }\right)$ did not vary with the electrolysis].

\section{Electrolysis in the presence of $\mathrm{KCl}$ Order with respect to $A B 1$}

In the presence of $\mathrm{KCl}$, the absorbance at $640 \mathrm{~nm}$ decreases with the time of electrolysis (Fig. 2), but at $480 \mathrm{~nm}$ increases. The time required for total discoloration or degradation is a function of the operational parameters which will be later discussed. A detailed discussion about the evolution of the UVvisible spectrum is given in the paragraph on the effect of $\mathrm{pH}$. At the $\mathrm{pH}(\mathrm{pH} 5)$ of the dye solution, the reaction occurred into two steps: the first one is fast and corresponds to a color change of the solution from deep blue to slight pink; and in a second step total discoloration occurred (slow step). So, the rate constant calculated in these conditions corresponds to the rate constant of the first step. The order with respect to $\mathrm{AB} 1$ is not clear; in fact, there is a strong competition between order zero and one. When studying the effect of temperature and the ionic force, the best order is zero (Fig. 2a), but when studying the effect of $\mathrm{KCl}$ 
concentration and current intensity, the best order is 1 (Fig. 2b), and finally, when studying the effect of dye concentration, for a given concentration, the best order is zero, and for other the best order is 1 .
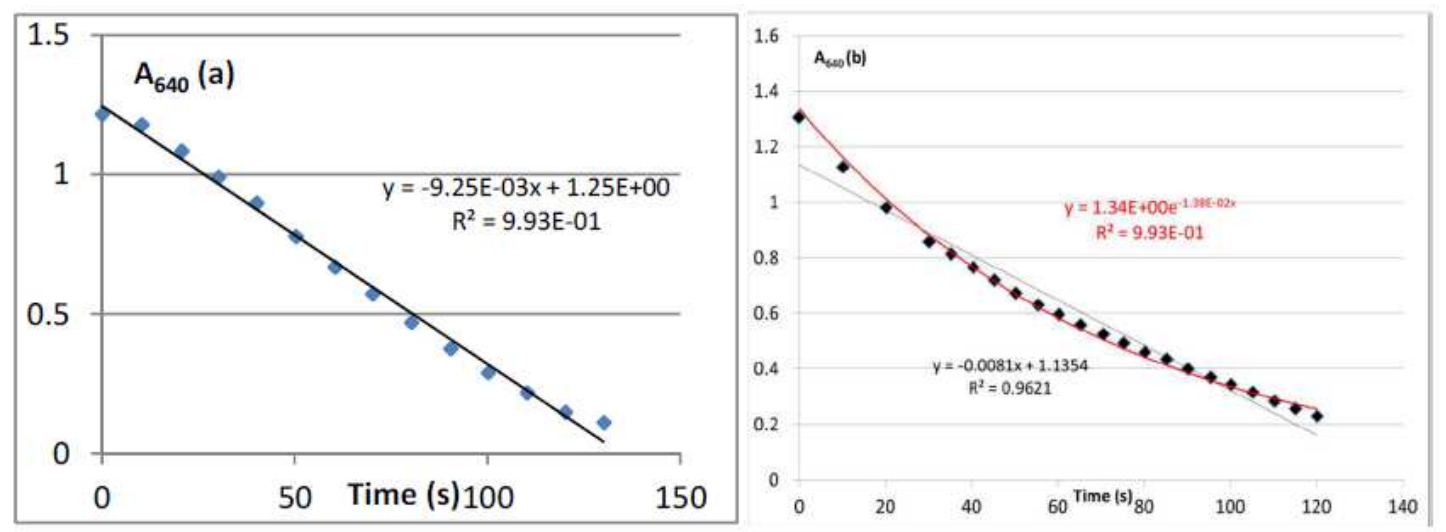

Figure 2. Order with respect to $\mathrm{AB} 1$ in the presence of $\mathrm{KCl} .20 \mathrm{~mL}$ of $40 \mathrm{mg} / \mathrm{L} \mathrm{AB} 1+$ $10 \mathrm{~mL}$ of $1 \mathrm{M} \mathrm{KCl}, \mathrm{pH} 5$, (total volume $100 \mathrm{~mL}$ ).(a):Effect of temperature at $5 \mathrm{~mA}$ and 290 K, (b): Effect of current intensity: 293 K, 20 mA.

\section{Effect of the food colorant concentration}

At BDD electrode, the discoloration rate constant, $\mathrm{k}_{\mathrm{o}, \mathrm{obs}}$ (slope of the line $\mathrm{A}_{640} \mathrm{vs}$. time), is approximately the same when the concentration varies in the range from 2 to $8 \mathrm{mg} \mathrm{L}^{-1}$ (4 different mixtures were prepared for this study); so, the rate constant $\mathrm{k}_{\mathrm{o}, \mathrm{obs}}\left(\mathrm{k}_{\mathrm{i}}\right.$ for order $\mathrm{i}$ ) does not vary with $\mathrm{AB} 1$ concentration, but the time needed to have total discoloration is proportional to the concentration of $\mathrm{AB} 1$.

\section{Effect of $p H$}

The UV-visible spectrum of $\mathrm{AB} 1$ aqueous solution shows three bands at $312 \mathrm{~nm}$ (smallest one), $414 \mathrm{~nm}$, and $640 \mathrm{~nm}$ (highest one). AB1 has an acid-base property with pka equal to 2.2. In $\mathrm{pH}$ lower than 1 , the $\mathrm{AB} 1$ solution is yellow $\left(\lambda_{\max }: 414 \mathrm{~nm}\right)$, and it is blue in $\mathrm{pH}$ higher than $3\left(\lambda_{\max }: 640 \mathrm{~nm}\right)$.

In $0.1 \mathrm{M} \mathrm{H}_{2} \mathrm{SO}_{4}$ : The solution is yellow. There is only one important band at 416 $\mathrm{nm}$ and a small one at $274 \mathrm{~nm}$. During electrolysis, there is a decrease in $\mathrm{A}_{414}$ accompanied by a progressive blue shift to $346 \mathrm{~nm}$, whereas the absorbance at $274 \mathrm{~nm}$ remains $\sim$ constant. The yellow color of the solution faded slowly. According to the literature, the progressive blue shift is attributed to the dealkylation of the amino groups and partial degradation of the dye (Fig. 3a) [24].

In $0.01 \mathrm{M} \mathrm{H}_{2} \mathrm{SO}_{4}$ : At the beginning, the visible spectrum shows two bands at 414 (more intense) and $640 \mathrm{~nm}$. In the first step of electrolysis, the absorbance at 640 $\mathrm{nm}$ decreases, but at $414 \mathrm{~nm}$ increases; then, the absorbance at $640 \mathrm{~nm}$ begins to increase with a blue shift to $628 \mathrm{~nm}$, and at $414 \mathrm{~nm}$ continues to increase. At the end, the bands at 414 and $628 \mathrm{~nm}$ begin to decrease with a progressive blue shift to $604 \mathrm{~nm}$ (spectra not shown here).

In $10^{-3} \mathrm{M} \mathrm{H}_{2} \mathrm{SO}_{4}$ : At first, the solution changes with time from green to yellow, and then it becomes slowly transparent. The $\mathrm{A}_{640}$ and $\mathrm{A}_{314}$ decrease, whereas $\mathrm{A}_{414}$ 
and $A_{272}$ increase to reach a maximum (Fig. 3b). The increase in $A_{414}\left(\lambda_{\max }\right.$ of the acidic form) isn't because of the decrease in the $\mathrm{pH}$ of the solution, since there is a reduction of $\mathrm{H}^{+}$on the cathode. Then, the absorbance at 640 begins to increase with a progressive blue shift to $604 \mathrm{~nm}$, and at 414 begins to decrease. There are several isobestic points at 284, 328 and $510 \mathrm{~nm}$. At the end, the absorbance at 640 and $414 \mathrm{~nm}$ decreases, but the absorbance below 370 increases with the appearance of a new band at $330 \mathrm{~nm}$ (the spectra of the second step are removed for clearness of the figure).

In water and in less basic medium $\left(10^{-4} \mathrm{M} \mathrm{NaOH}\right)$ : The evolution of the UVvisible spectrum in both mediums is approximately the same - the spectrum shows three bands at 314, 414, and $640 \mathrm{~nm}$. A new large band appears with time $(350 \mathrm{~nm}-558 \mathrm{~nm})$. At first, the solution changes from deep blue to slight pink, and then it becomes slowly transparent. There is a decrease in $\mathrm{A}_{640}$ and $\mathrm{A}_{314} \mathrm{~nm}$, but an increase in $\mathrm{A}_{480}$ and $\mathrm{A}_{274} \mathrm{~nm}$; the absorbance at $414 \mathrm{~nm}$ remains $\sim$ constant with time (Fig. 3c). The decrease in $\mathrm{A}_{640} \mathrm{~nm}$ is linear with time, so, the order with respect to the discoloration of $\mathrm{AB} 1$ is zero. The rate constant decreases with the increase in $\mathrm{pH}$. There are also three isobestic points at 294, 332 and $558 \mathrm{~nm}$. After a certain time, the absorbance at $480 \mathrm{~nm}$ begins to decrease, and the absorbance at $640 \mathrm{~nm}$ continues to decrease, accompanied by the appearance of a new band at $274 \mathrm{~nm}$ (Fig. 3c).

In basic medium $\left(10^{-3} \mathrm{M} \mathrm{NaOH}\right)$ : The UV-visible spectrum shows three bands at 314, 414, and $640 \mathrm{~nm}$. These three bands decrease during electrolysis (Fig. 3d). The color of the solution passes from deep blue to transparent, without passing through the pink color. The same trend is observed in the presence of sulfate at the $\mathrm{pH}$ of the dye solution. Comparing the evolution of the UV-visible spectrum of $\mathrm{AB} 1$ during electrolysis with that in ref. 20, we can say that total degradation of $\mathrm{AB} 1$ occurred in basic medium in the presence of $\mathrm{KCl}$.

It is obvious that the $\mathrm{pH}$ of the medium is an important parameter which affects the mechanism of the reaction. HPLC MS will be helpful to determine the mechanism of the indirect oxidation of AB1.

The comparison between the AB1 dye, crystal violet $(\mathrm{CV})$ and malachite green (MG), with respect to the evolution of the UV-visible spectrum, shows different behaviors: in the case of $\mathrm{CV}$, the solution changes from pink to faded blue during electrolysis.

The decrease in $\mathrm{A}_{590}$ is accompanied by a bathochromic shift, due to the substitution of chlorine on the phenyl ring(s), or the deamination of one amino group (leading to an increase in resonance as in $\mathrm{MG}$ ), then, degradation of the dye (Fig. 4a)). In the case of MG, which has two amino groups, the behavior is similar to $\mathrm{AB} 1$; in the first step, there is an increase in the region between 430 and $500 \mathrm{~nm}$, and a decrease in the band at $640 \mathrm{~nm}$, and the absorbance at 426 remains $\sim$ constant (Fig. 4b).

\section{Effect of the current intensity}

Current intensity is also an important parameter in electrolysis. The generation of chlorine species by electrolysis was done at $\mathrm{pH}(\mathrm{pH}$ 5) of the dye solution in the presence of $8 \mathrm{mg} \mathrm{L}^{-1}$ of $\mathrm{AB} 1$ and $0.1 \mathrm{M} \mathrm{KCl}$ (as final concentrations), at five 
constant currents ranging from $1 \mathrm{~mA}$ to $20 \mathrm{~mA}$. As expected, the degradation rate constant increases linearly with the increase of the current intensity $\left(\mathrm{k}_{1 \mathrm{obs}} \mathrm{X} 10^{3}=\right.$ $0.688 \times \mathrm{I}(\mathrm{mA}), \mathrm{R}^{2}$ : 0.997). The increase in the degradation rate is related to the increase in the production rate of chlorine species. Similar results were obtained with other organic compounds $[25,26]$.
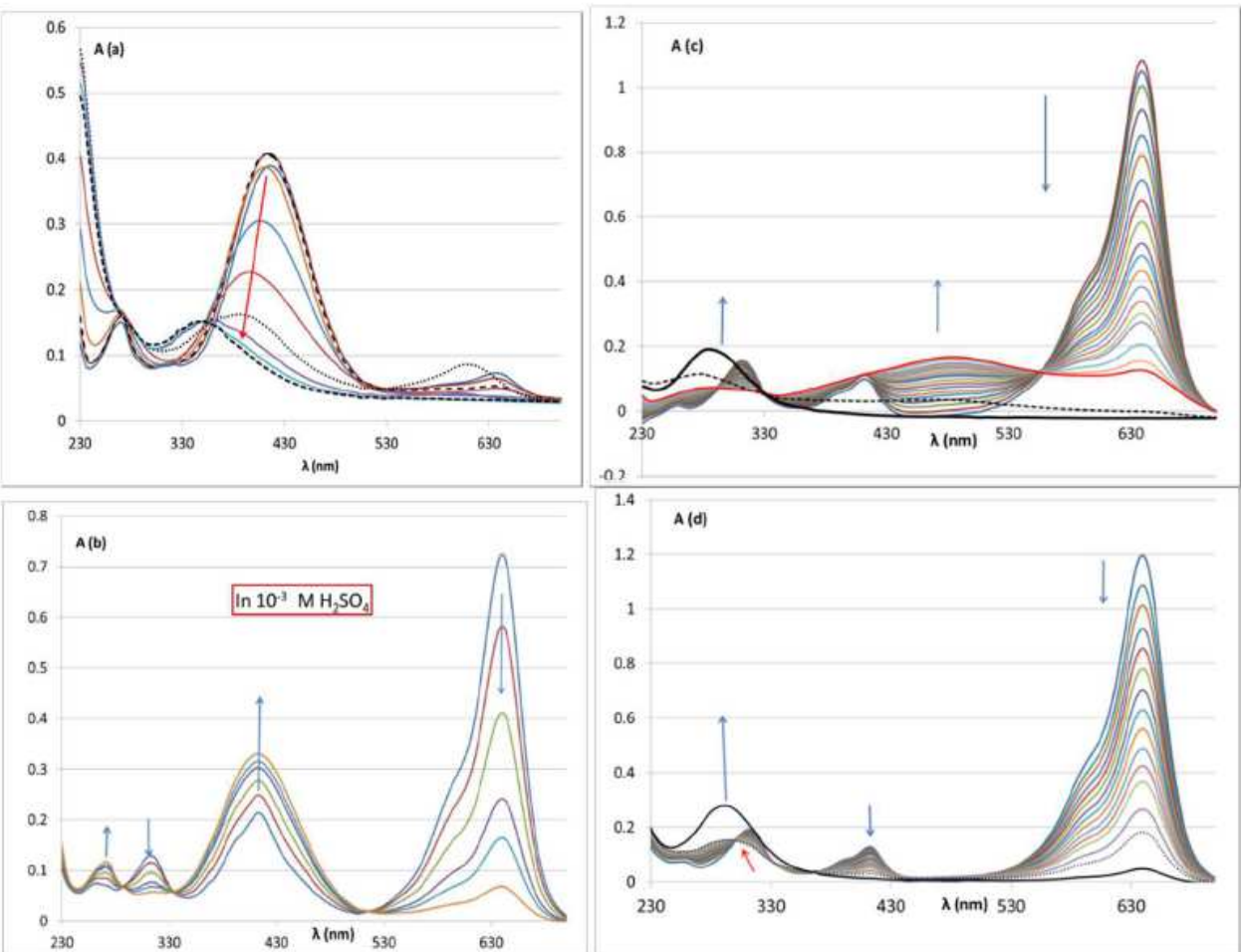

Figure 3. Variation of the UV-visible spectrum of the mixture $\mathrm{AB} 1 / \mathrm{KCl}$ during electro degradation. $25 \mathrm{~mL}$ of $40 \mathrm{mg} / \mathrm{L} \mathrm{AB} 1+10 \mathrm{~mL} 1 \mathrm{M} \mathrm{KCl}$ (total volume: $100 \mathrm{~mL}$ ), at 10 $\mathrm{mA}$. a: in $0.1 \mathrm{M} \mathrm{H}_{2} \mathrm{SO}_{4}$, b: in $10^{-3} \mathrm{M} \mathrm{H}_{2} \mathrm{SO}_{4}$, c: in $10^{-4} \mathrm{M} \mathrm{NaOH}$, d: in $10^{-3} \mathrm{M} \mathrm{NaOH}$.
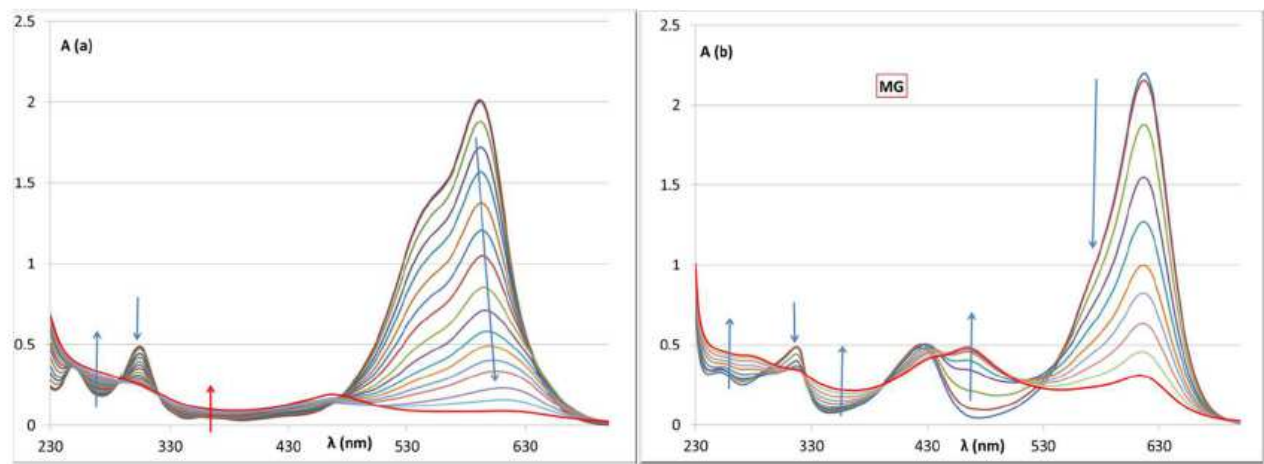

Figure 4. UV-visible spectra of the mixture $\mathrm{CV} / \mathrm{KCl}$ (a) and $\mathrm{MG} / \mathrm{KCl}$ (b) during the electrodegradation. (800 s), $5 \mathrm{~mA}$ and at $293 \mathrm{~K}$.

\section{Effect of $\mathrm{KCl}$ concentration}

The effect of $\mathrm{KCl}$ concentration on the degradation rate was undertaken in the following conditions: $0 \mathrm{M} \leq[\mathrm{KCl}] \leq 0.2 \mathrm{M}$ (KCl added), $8 \mathrm{mg} \mathrm{L}^{-1}$ of $\mathrm{AB} 1, \mathrm{pH}_{\mathrm{o}}$ $5,293 \mathrm{~K}$, with $5 \mathrm{~mA}$. The rate constant increases linearly with the increase in $\mathrm{KCl}$ concentration $\left(\mathrm{k}_{1, \mathrm{obs}} \times 10^{3}: 0.87 \mathrm{x}[\mathrm{KCl}](\mathrm{M})+2.5, \mathrm{R}^{2}: 0.986\right)\left(\mathrm{k}_{1, \mathrm{obs}}\right.$ : slope of 
the line $\ln \mathrm{A}$ vs. time). The reason is that a higher amount of chlorine/hypochlorite will be generated, while increasing the chloride concentration, due to the increased mass transport of chloride ions to the anode surface [25]. This result confirms the discoloration and the degradation of the organic compounds via the electro-generated chloride species [26, 27]. The discoloration of the rate constant is not negligible when the volume of $\mathrm{KCl}$ added is zero, since the powder of AB1 contains already sulfate and chloride as impurities.

\section{Effect of the ionic force}

In the presence of a constant concentration of $\mathrm{KCl}(0.1 \mathrm{M})$, the rate constant $\mathrm{K}_{\mathrm{o}}$ remains approximately constant with the increase of the ionic force by addition of several volumes of $1 \mathrm{M} \mathrm{Na}_{2} \mathrm{SO}_{4}$ (7 different mixtures were prepared for this study). Maybe this is because the powder of the food colorant already contains $50 \%$ of inorganic salts (sulfate and chloride).

\section{Effect of temperature}

In general, any increase in temperature decreases the solubility of $\mathrm{Cl}_{2}$ in water and, therefore, decreases the discoloration rate constant of the dyes [28]. The effect of the temperature on the degradation rate was investigated with the conditions mentioned in the caption of Fig. 5a.

For the range of temperature between 280 and $303 \mathrm{~K}, \mathrm{k}_{\mathrm{o}}$ decreases linearly with the increase of temperature $\left(\mathrm{K}_{0} \times 10^{3}=-0.2 \times \mathrm{T}(\mathrm{K})+67.5, \mathrm{R}^{2}: 0.989\right)$.
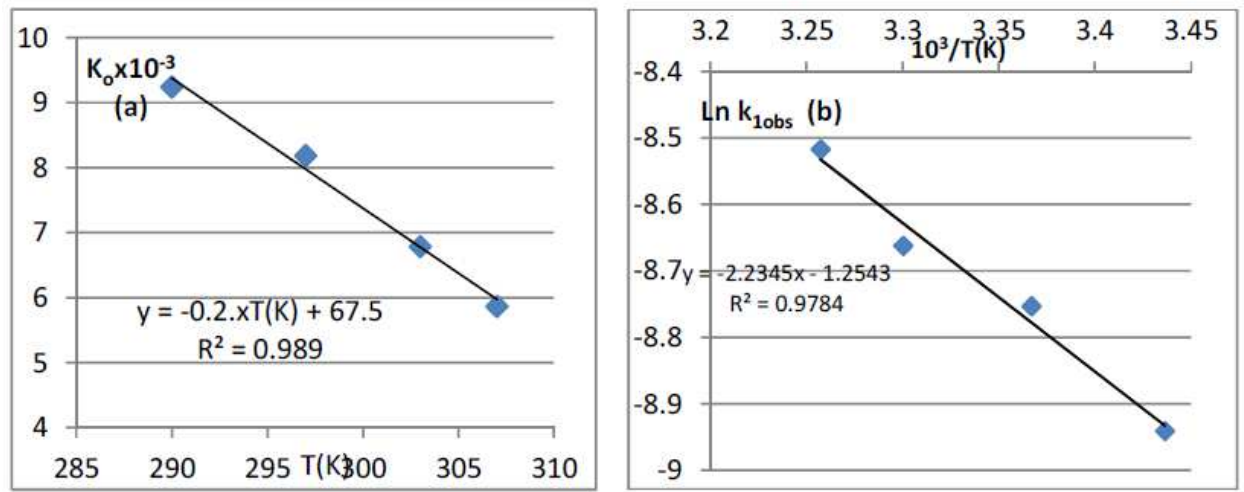

Figure 5. Effect of the temperature on the electrodegradation of $\mathrm{AB} 1$ by $\mathrm{KCl}$ (a), and by $\mathrm{Na}_{2} \mathrm{SO}_{4}$ (b). $20 \mathrm{~mL}$ of $40 \mathrm{~mL} / \mathrm{AB} 1+10 \mathrm{~mL}$ of $1 \mathrm{M} \mathrm{KCl}$ at $5 \mathrm{~mA}$ (total volume 100 $\mathrm{mL}$ ). $20 \mathrm{~mL}$ of $40 \mathrm{~mL} / 1 \mathrm{AB} 1+10 \mathrm{~mL}$ of $1 \mathrm{M} \mathrm{Na}_{2} \mathrm{SO}_{4}$ at $20 \mathrm{~mA}$ (total volume $100 \mathrm{~mL}$ ).

\section{In the presence of $\mathrm{KBr}$}

In the presence of $\mathrm{KBr}$, the decrease in the $\mathrm{A}_{640}$ is four times faster than in the presence of $\mathrm{KCl}$. 


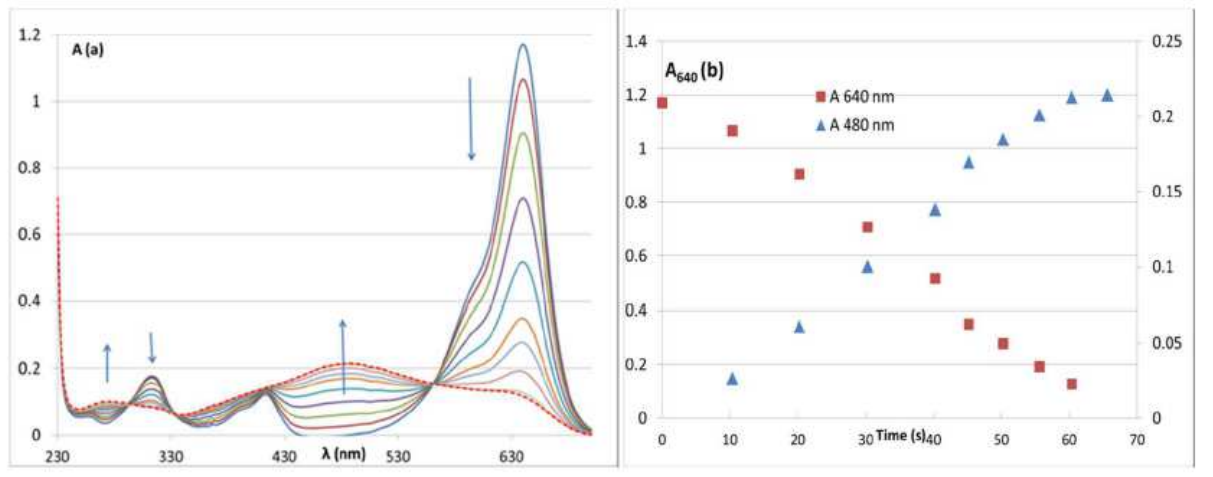

Figure 6. Variation of the UV-visible spectrum of the mixture $\mathrm{AB} 1 / \mathrm{KBr}(\mathrm{a})$, variation of the absorbance at 640 and $480 \mathrm{~nm}$ (b) during electrolysis. $20 \mathrm{~mL}$ of $40 \mathrm{mg} / \mathrm{L}$ of $\mathrm{AB} 1$ $+10 \mathrm{~mL}$ of $1 \mathrm{M} \mathrm{KBr}, 2 \mathrm{~mA}$ (total volume $100 \mathrm{~mL}$ ).

At $\mathrm{pH}(\mathrm{pH} \sim 5)$ of the dye solution, the general shape of the spectrum vs. time is similar to that in the presence of $\mathrm{KCl}$ : there is a decrease in the absorbance at 640 $\mathrm{nm}\left(\lambda_{\max }\right)$, accompanied with an important increase in the absorbance in the zone from 414 to $560 \mathrm{~nm}$ (new band, $\lambda_{\max }: 480 \mathrm{~nm}$ ) (Fig. 6a). The discoloration passes by two steps: the first one is fast and corresponds to a change of color from blue to brown pink; the second one is slower and corresponds to total discoloration. In the first step, the absorbance at $480 \mathrm{~nm}$ increases linearly with time. By varying the concentration of $\mathrm{KBr}$ in the medium, the order of the first step with respect to $\mathrm{AB} 1$ remains zero (Fig. 6b), and the rate constant remains $\sim$ constant (five different mixtures were prepared for this study). In the absence of $\mathrm{KBr}$, the rate constant is not zero, since the sample already contains a strong electrolyte as impurities $(50 \%)$.

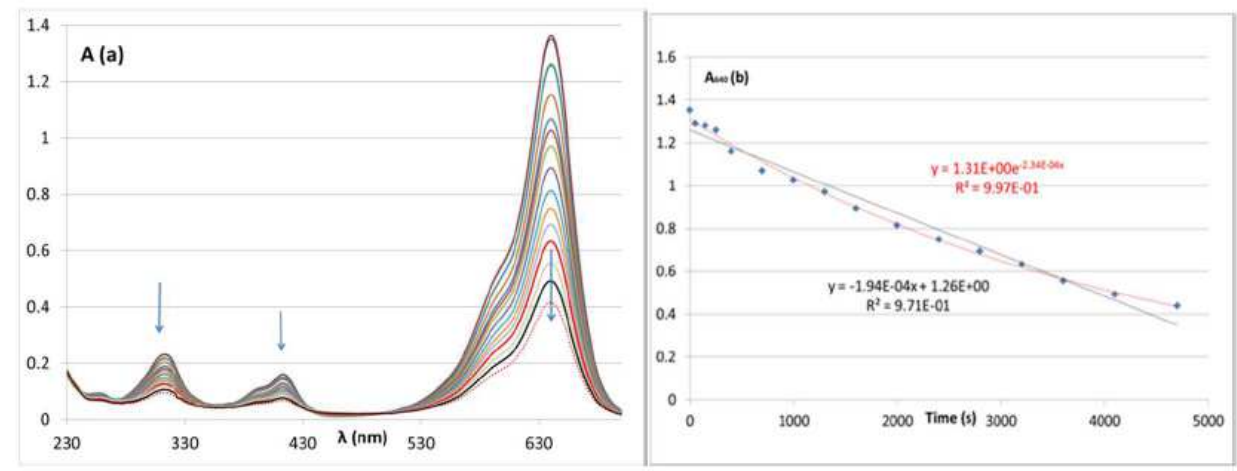

Figure 7. (a) Variation of the UV-visible spectrum of the mixture AB1/ sulfate during $1.4 \mathrm{~h}$. (b) Order with respect to $\mathrm{AB} 1$ in the presence of sulfate. $20 \mathrm{~mL}$ of $40 \mathrm{mg} / \mathrm{L} \mathrm{AB} 1$ $+20 \mathrm{~mL} \mathrm{Na}_{2} \mathrm{SO}_{4}+20 \mathrm{~mA}$ (total volume $100 \mathrm{~mL}$ ).

\section{In the presence of sulfate}

The discoloration in the presence of sulfate is very low with $5 \mathrm{~mA}$; for this reason, the discoloration is done with $20 \mathrm{~mA}$ (more than $2 \mathrm{~h}$ are needed to have total discoloration, with $20 \mathrm{~mA}$, Fig. 7). In the same conditions, the rate constant is 40 times lower than in the presence of $\mathrm{KCl}$. The behavior in the presence of sulfate is completely different, with no new band or isobestic point observed, but 
with a decrease in the whole spectrum with time (Fig. 7a). The blue color faded progressively; no intermediate color is observed during the reaction, as was the case with $\mathrm{KCl}$ and $\mathrm{KBr}$, where the blue color of $\mathrm{AB} 1$ turns pink to brown with time, and then becomes transparent. The best order with respect to AB1 is order 1 (Fig. 7b) (similar order is observed with malachite green [20]). According to the literature, in the presence of sulfate, AB1 undergoes total discoloration [17]. With a constant concentration of sulfate $(0.05 \mathrm{M})$, the increase in the food color concentration leads to a negligible decrease in the $\mathrm{k}_{1 \mathrm{obs}}$ rate constant. The increase in the concentration of sulfate in the medium from 0.05 to $0.4 \mathrm{M}$ has no effect on the $\mathrm{K}_{\text {lobs }}$ rate constant. The increase in $\mathrm{pH}$ from 1 to 4 causes a slight increase in the rate constant, from $1.35 \times 10^{-4}$ to $2.08 \times 10^{-4}$ (four different mixtures were prepared to study every parameter). Similar results are obtained with the electrodegradation of $\mathrm{CV}$ on the BDD electrode [17]. Finally, the increase in temperature increases the degradation rate of AB1 (Fig. 5b). Similar effect is observed with other organic compounds on BDD electrode [29, 30].

The activation parameters associated with the discoloration are calculated as follows: the plot of $\ln \mathrm{k}_{\text {lobs }} \mathrm{vs}$. 1/T gives the value of the activation energy (Ea), according to Arrhenius equation:

$$
\ln K_{o b s}=-E_{a} / R T+c t e \quad \text { with } R: 8.3 J . K^{-1} . m^{-1}
$$

The $\Delta \mathrm{H}^{\ddagger}, \Delta \mathrm{S}^{\neq}$and $\Delta \mathrm{G}^{\#}$ values can be calculated from the two equations:

$$
\ln \left(\frac{K_{o b s}}{T}\right)=\left(\ln \frac{k_{B}}{h}+\frac{\Delta S^{\neq}}{R}\right)-\frac{\Delta H^{\ddagger}}{R \times T}, \quad \Delta G^{\#}=\Delta H^{\#}-T \Delta S^{\#}, \quad \ln \left(\frac{k_{B}}{h}\right)=23.76
$$

The activation energy and the other kinetic parameters in the range of temperature studied $\left(18{ }^{\circ} \mathrm{C}-34^{\circ} \mathrm{C}\right)$ are listed in Table 1.

Table 1. Activation thermodynamic parameters of the electrodegradation of $\mathrm{AB} 1$ by sulfate. $8 \mathrm{mg} \mathrm{L}^{-1} \mathrm{AB} 1,0.05 \mathrm{M}$ sulfate, $20 \mathrm{~mA}, \mathrm{pH} \sim 5$.

\begin{tabular}{|c|c|c|c|c|}
\hline KCl & $290 \mathrm{~K}\left(9.25 \times 10^{-3}\right)$ & $297 \mathrm{~K}\left(8.19 \times 10^{-3}\right)$ & $303 \mathrm{~K}\left(6.79 \times 10^{-3}\right)$ & $307 \mathrm{~K}\left(5.87 \times 10^{-3}\right)$ \\
\hline sulfate & $291 \mathrm{~K}\left(1.31 \times 10^{-4}\right)$ & $297 \mathrm{~K}\left(1.58 \times 10^{-4}\right)$ & $303 \mathrm{~K}\left(1.73 \times 10^{-4}\right)$ & $307 \mathrm{~K}\left(2 \times 10^{-4}\right)$ \\
\hline sulfate & $\mathrm{E}_{\mathrm{a}}\left(\mathrm{kJ} \cdot \mathrm{mol}^{-1}\right)$ & $\Delta \mathrm{H}^{\ddagger}\left(\mathrm{kJ} \cdot \mathrm{mol}^{-1}\right)$ & $\Delta \mathrm{S}^{\ddagger}\left(\mathrm{kJ} \cdot \mathrm{mol}^{-1} \cdot \mathrm{K}^{-1}\right)$ & $\Delta \mathrm{G}_{298}{ }^{\mp}\left(\mathrm{kJ} \cdot \mathrm{mol}^{-1}\right)$ \\
\hline & 18.5 & 16.1 & -0.263 & 90.58 \\
\hline
\end{tabular}

The values between parenthesis correspond to the rate constant.

\section{Conclusions}

At BDD electrode, the discoloration of $\mathrm{AB} 1$ in the presence of sulfate is too much slower than in the presence of $\mathrm{KCl}$ and $\mathrm{KBr}$. The increase in the current intensity, the dye concentration, and the ionic force follow identical behaviors in both kind of salts, but the same does not happen with respect to the temperature. Total degradation occurred in the presence of sulfate and in the presence of $\mathrm{KCl}$ in a basic medium. In the presence of $\mathrm{KCl}$, the $\mathrm{pH}$ of the medium strongly affects the reaction mechanism; HPLC MS will help us have an idea about the intermediates of the reaction at different $\mathrm{pH}$ and confirm if there is total degradation. 


\section{Acknowledgements}

The author thanks the Lebanese University for providing financial assistance to carry out this work.

\section{References}

1. Robinson T, McMullan G, Marchant R, et al. Bioresource Technol. 2001;77:247.

2. Fonovich TM. Drug Chem Toxicol. 2012;36:343.

3. Inetianbor JE, Yakubu JM, Ezeonn SC. Asian J Sci Technol. 2015;6:1118.

4. EFSA Journal, Parma, Italy, 2013:11(3):2818, "Re-evaluation of Patent Blue V (E 131) as a food additive"

5. Rammal RS, Zatiti SA, El Jamal MM. JUCTM (Sofia). 2011;46:283.

6. Bulut E, Ozacar M, Sengil IA. Microp Mesop Mater. 2008;115:234.

7. Lucova M, Hojerova J, Pazourekova S, et al. Food Chem Toxic. 2013;52:19.

8. Chaube P, Indurkar H, Moghe S. Asiatic J Biotech Res. 2010;1:45.

9. Diao Z-H, Xu X-R et al. Sep Purif Technol. 2015;154: 168.

10. Barka N, Qourzal S, Assabbane A, et al. Chem Eng Comm. 2011;198:1233.

11. Chen C-C, Fan H-J, Jan J-L. J Phys Chem C. 2008;112:11962.

12. Saquib M, Tariq MA, Faisal M, et al. Desalination. 2008;219:301.

13. Gosetti F, Gennaro MC, et al. J Chromatography A. 2004;1054:379.

14. Fayoumi LMA, Ezzedine MA, Akel HH, et al. Port Electrochim Acta. 2012;30:121.

15. Elddine HAN, Damaj ZK, Yazbeck OA, et al. Port Electrochim Acta. 2015;33:275.

16. Nava JL, Quiroz MA, Martínez-Huitle CA. J Mex Chem Soc. 2008;52:249.

17. Palma-Goyes RE, Torres-Palma RA, et al. Chemosphere. 2010;81:26.

18. Hamza M, Abdelhedi R, Brillas E, et al. J Electroanal Chem. 2009;627:41.

19. Rao ANS, Venkatarangaiah VT. Port Electrochim Acta. 2014;32:213.

20. Guenfoud F, Mokhtari M, Akrout H. Diamond Related Mater. 2014;46:8.

21. Martínez-Huitle CA, Alfaro MAQ, J Environ Eng Manag. 2008;18:155.

22. Enache TA, Chiorcea-Paquim A-M, Fatibello-Filho O, et al. Electrochem Comm. 2009; 11:1342.

23. Souza RBA, Ruotolo LAM. Int J Electrochem Sci. 2013;8:643.

24. Chen C-C, Lu C-S, Mai F-D, et al. J Haz Mat. 2006; B137:1600.

25. Rajkumar D, Jong GK. J Haz Mat. 2006;B136:203.

26. El Jamal MM, Mousaoui AM, Naoufal DM, et al. Port Electrochim Acta. 2014;32:233.

27. Tabarra MA, Mallah HA, El Jamal MM. J Chem Technol Metall (Sofia). 2014;49:12.

28. Schmittinger P. Chlorine. In: Ullmann's Encyclopaedia, vol. 6A. Weinheim: VCH; 1986. P. 399.

29. Chen T-S, Kuo Y-M, Chen J-L, et al. Int J Electrochem Sci. 2013;8:7625

30. Chen T-S, Huang K-L. Int J Electrochem Sci. 2013;8:6343. 